American Journal of Applied Sciences 6 (1): 30-42, 2009

ISSN 1546-9239

(C) 2009 Science Publications

\title{
Base Course Modification through Stabilization using Cement and Bitumen
}

\author{
${ }^{1}$ S.M. Marandi and ${ }^{2}$ P. Safapour \\ ${ }^{1}$ Department of Civil Engineering, \\ ${ }^{2}$ Department of Computer Engineering, \\ Shahid Bahonar University, Kerman, Iran
}

\begin{abstract}
The main objectives of this research was to analyze the use of combined cement and bitumen emulsion in base course stabilization in details and examine its replacement with conventional pavement in regions with low quality materials and limited construction period. To conduct the objectives, the research divided into three phases. Phase I involved the optimization of cement and bitumen emulsion. In this case, a series of Indirect Tensile Strength (ITS), Unconfined Compressive Strength (UCS) and Marshal Tests carried out. In the second phase, various alternative roadway sections examined for minimizing the pavement thickness and increasing the bearing capacity and finally in third phase, a Falling Weight Deflectometer (FWD) machine used to examine the pavement bearing capacity for three sections of the roadway. It was found that, the optimum values to eliminate the creation of shrinkage cracks in the whole project and minimize the execution period and construction costs were $3 \%$ for both binders in stabilization and its replacement with conventional pavement method (i.e., stabilized layer with conventional sub-base and base layers). Also, FWD results showed that, the bearing capacity of the constructed pavement using stabilization method is far beyond the predicted values in pavement design. Furthermore, it was found that, with high inflation rate and political situation in the region, base stabilized method decreased the final roadway construction costs in compare with conventional pavement method.
\end{abstract}

Key words: Dynamic deflectometer, cement and emulsion, stabilization technology

\section{INTRODUCTION}

A huge amount of investments are used for maintenance, construction and extending roads and freeways in many countries. Statistics shows that during last fifty years, the most investments are used on roads in compare to other general infrastructures ${ }^{[1]}$.

The roads built with conventional methods do not satisfy the huge volume of loads no more. However, in undeveloped and developing countries such as Afghanistan, which are many limitations (e.g., limited time schedule because of internal civil war, lack of good quality material, over loading passing trucks and budget), the conventional methods may be cost and execution time effective. Thus, new methods must be adopted for new roads to increase the bearing capacity of the pavements.

The concept of soil modification through stabilization with additives has been around for several thousand years ${ }^{[2]}$. Even today, stabilization with manufactured additives such as lime, lime fly ash,
Portland cement, bituminous materials, fibers and geosynthetics are gaining popularity in many parts of the world $^{[3]}$. Attention has been focused on substitute materials such as stabilized soils.

Chemically modified soils often change surface molecular properties of the soil grains and, in certain cases, the grains are cemented together, resulting in an increase in strength and improvement of other desired engineering properties ${ }^{[4]}$.

In the cement stabilization, the cement and water, when combined, from cementations calcium silicate hydrate and aluminates hydrates, which bind soil particles together and make the matrix compact ${ }^{[4]}$.

Stabilization of soils and aggregates with bitumen differs greatly from cement stabilization. The basic mechanism involved in bitumen stabilization is a waterproofing phenomenon. Soil particles are coated with bitumen that prevents or slows the penetration of water, which could normally result in a decrease in soil strength. In addition, bitumen stabilization can improve durability characteristics by making the soil resistant to

Corresponding Author: Dr. Seyed Morteza Marandi, Department of Civil Engineering, 22 Bahman Blvd., Bahonar University, P.O. Box 76175-133, Kerman, Iran Tel/Fax: + (98) 341-2462722 Mobile: + (98) 913-1404195 
the detrimental effects of water such as volume. In noncohesive materials, such as sand and gravel, crushed gravel and crushed stone, two basic mechanisms are active: waterproofing and adhesion. The bitumen coating on the cohesionless materials provides a membrane, which prevents the penetration of water and thereby reduces the tendency of the material to lose strength in the presence of water ${ }^{[5]}$.

The role of combined cement and bitumen emulsion is to increase the stiffness and elasticity of the stabilized layer. However, to find a correlation between the laboratory and field results, more data is needed to establish a pavement design specification for stabilized base layer using combined cement and bitumen emulsion.

The main objectives of this research was to analyze the use of combined cement and bitumen emulsion in base course stabilization in details and examine its replacement with conventional pavement in regions with low quality materials and limited construction period. The results believed to contribute a better insight into the combined cement and bitumen emulsion behavior and obtaining new data for future theoretical pavement analysis.

To conduct the objectives, a study was carried out to examine the potential of using a stabilized base using combined bitumen emulsion and cement for paving the various road projects in Heart-Afghanistan.

Herat is the largest city in western Afghanistan and is the main trade city for exports to Iran and now Turkmenistan and Middle East. The main road connecting Iran to Heart is one of the busiest roads in Afghanistan with most of the exports from Afghanistan and southwest Pakistan going through this route to Turkmenistan through border city of Torghundi.

Herat-Dogharoun main road project with $122 \mathrm{~km}$ in length, that had been intended primarily, using conventional method, was designed and executed with base stabilized method using cement and bitumen emulsion and compared with conventional pavement. New data was found for optimizing cement and emulsion. Furthermore, the constructed $122 \mathrm{~km}$ roadway was monitored for behavior of the layers and their effects on pavement bearing capacity.

In spite of many researches carried out on soil stabilization using various additives including lime, lime fly ash, Portland cement, bituminous materials, fibers and geo-synthetics in many parts of the world, the results have been mixed. To date, there has been no standard method for designing cement-bitumen emulsion stabilized mixes. However, more research must be carried out to obtain new data for standardizing the method. The new contributions may be using in future theoretical analysis.

\section{OPERATION EQUIPMENTS}

During the construction project on the stretch from Dogharoun to Heart a stabilized bearing course with a length of $122 \mathrm{~km}$ was constructed from natural gravel and sand material by in-place stabilization using cement and bitumen emulsion as binding agent. The bases of the project was the newly formulated Austrian RVS 85.05.13, it describes the technical and legal conditions for the construction of stabilized bearing courses when using different binding agents or combinations of binding agents. Only soil stabilizers with appropriate dosing facilities guaranteed a consistently mixing quality. A constant working depth and the requisite dosing exactitude of water and binding agent were considered for the implementation of this RVS and the applied construction procedure. Therefore, two stabilizers, two 19 tons single drum rollers for uniform and optimal compaction of the bitumen-cement soil mixture and a tandem roller was provided.

The stabilizers fitted with water and bitumen emulsion and dosing equipment. The miller, working weight 20 tons, engine power $300 \mathrm{~kW}$, working width $2.50 \mathrm{~m}$ and maximum working depth $400 \mathrm{~mm}$, has a combined buckle and back axle steering, all-wheel drive, hydrostatic operating, rotor drive and automatic performance control. The rotor has 210 milling chisels and rotates opposite to the working direction. The number of rotations can be set in 11 levels between 100 and 170 rotations $\mathrm{min}^{-1}$. and/or set according to the requirements of the construction. The construction of the rotor cover with a variable rear hatch allows thorough mixing of the ground, binder and water components and even surfacing of the stabilized layer. The bitumen emulsion equipment with the bitumen pump, spraying beam and special nozzles for the spread of the bitumen emulsion has an easy to use manual dosing system for the control of the spray content. The nozzles can be dually controlled so that for overlapping and construction on the shoulders, the working width can be varied. A separate water-spraying beam with speed independent dosing system enables optimal moisture content for the base course material. A bitumen emulsion tank wagon, $10000 \mathrm{~L}$, in front of the ground stabilizer and a water tank wagon, $7000 \mathrm{~L}$, behind it supply the stabilizer with binder and water.

For the main compaction of the stabilized layer two 19 tons roller trains used, which guaranteed secure and thorough compaction of the bitumen emulsion-cementground mixture. The roller trains were equipped with the measuring system for controlling the compaction level, which carried out a measurement approximately every $40 \mathrm{~mm}$. 
Working process-included delivery of the gravelsand mixture, distribution of the material by graders and pre-compaction with single drum rollers to $\geq 95 \%$ proctor density (to produce a stable sub-layer for stabilization). A spreader mounted on a three axle's truck applies cement to the surface, which had previously been wetted because of the strong wind in the project area. The spreader had a capacity of 10 tones with cement spreading electrical control, which was able to spread cement precisely and independent of truck velocity. The spreader's auger and chain voids enabled the cement to spread with exact width of $2.5 \mathrm{~m}$. For application of roads shoulders and intermediate strips, the spreading width decreases to $0.80-1.70 \mathrm{~m}$.

The cement was mixed into the soil by stabilizer with a working speed of $6 \mathrm{~m} \mathrm{~min}^{-1}$. and a cutting depth of $250 \mathrm{~mm}$ and simultaneously dosing and applying bitumen emulsion and water into the layer across $8 \mathrm{~m}$ width of the road. A 19 tons roller takes care of the precompaction of the stabilized layer, which is leveled by a grader and finally is compacted by the second 19 tons roller.

To guarantee the predicted compaction of stabilized soil using cement and bitumen emulsion, 19 tons rollers were equipped with vario-control system and the results were subsequently printed out in the machine. Vario-control system is mounted inside the drum and at any position; the maximum compaction energy applies automatically. This system analyses the stiffness between the material and the drum. The requirement vibration at any angle between vertical and horizontal with amplitudes of $2.5 \mathrm{~mm}$ and centrifugal force equivalent to $500 \mathrm{kN}$ will produce.

To determine the modulus of elasticity and to control the quality of the sections performed, a FWD machine was used. The structural condition of a multilayered traffic lane during utilization can be determined by the deflections (deformations) caused by heavy traffic. With these known deflections under a controlled load and with the assumption of a suitable model, it is possible to back-calculate the material-constants and the stress and strains in a multi-layered pavement structure. They are basis for further design calculations.

The applied dynamic impulse load will cause the biggest deflection at the center of load and corresponding lower deflection values at distances away from the center of load. Connecting these single deflection values graphically a so-called deflection basin is determined. If the resulting stresses and strains resulting from a controlled load in a single structural layer are compared with the allowable material constants for materials used in connection with allowable load-repetitions, the structural condition of a multi-layer pavement can be evaluated and the service live can be estimated.

To enable the back-calculation of the elastic modulus of the single (individual) layers of a pavement, the thickness of this layer must be known (e.g., determined by geo-radar or by means of extracting cores drilled) as well as the deflection-basin.

The use of FWD machine enables the operator to determine the deflection-basin caused by a controlled load. The load application occurs with a defined mass, dropped from a defined height on a spring system with a base plate located on the surface of the pavement. The falling mass (weight) produces a dynamic impulse load with load duration of 25 mille second into the pavement. The loading time simulates a moving wheel load (vehicle) with a speed of $50 \mathrm{~km} \mathrm{~h}^{-1}$. Depending on the falling weight; a maximum load impulse of $250 \mathrm{kN}$ can be applied. The selected size of the load impulse for the measurement depends on the actual loads on the pavement caused by the traffic. If in fact shorter load times occur, they can be taken into consideration during evaluation.

The measured deflections are basis for the calculation of the E-Modules of the individual layers of the structure. Based on the deflection values, homogeneous sections are formed depending on the construction.

For the evaluation the initial assumption is made, that for each homogeneous section of the construction the mean and Standard deviation are the characteristic values.

The back-calculation of the E-Modules is done with special software e.g., PAVERS or PADS. The basis for calculation of flexible multi-layered pavements, a linear-elastic, homogeneous and isotropic material behavior is assumed. Based on a first assumption of E-Modules, the deformation for a load similar to the one applied during load bearing capacity measurements for the structure is calculated and it is varied for so long until it agrees with the actual measured values. The approximation to the actual values is done by means of iteration starting from the lowest laying layer up to the top layer and from the view of the situation of the geophones from the remotest to the nearest, meaning from the sub-grade up to the unbound layers and then to the top bound layers of the structure.

All depressions below the geo-phones (sensors) are considered for the calculation of the E-Modules, but they are weighted different depending on the measuring position. The calculations with the help of multi-layered 
systems are in good agreement with the actual behavior of the single structural layers under load.

A first approximation of the Module for the subgrade (underground) is derived from the called surface modules. From the progress of the surface module one can read the influence of the sub-grade, on the remotest geo-phones, for the base courses on geo-phones 5 and 4 and for the top bound layers on geo-phones 1 to 3 (usually, 7 geo-phones are set from the application of dynamic load).

Additional to the surface module the stiffness progress in the pavement becomes clear. With help of this first approximation value and the assumption of the modules for the top layers, an as good as possible agreement, by means of step-wise variation of input values, with the deflection basin from the measurements and the one determined by calculation is targeted.

With this iteration procedure the actual E-Modules of the individual structural layers can be assigned, making use of the assumed E-Modules. Finally the occurring stresses and strains in the pavement structure during the service life, depending on the actual loads, can be determined. From these calculations, the service life of the pavement structure can be estimated.

The calibration of the measuring equipment, the recording and the evaluation of the measured data are based on the findings in the COST 336 reports $^{[6]}$.

\section{DESIGN AND TESTING PROGRAM}

The continually classified rounded gravel materials, which are to be used for the construction of the stabilized layer, are excavated from 6 different excavation sites along the $122 \mathrm{~km}$ long section after determination of their suitability. For each of these excavation sites a mix design had to be set up for the material which was to be stabilized.

In addition to Austrian requirements of RVS 8S.05.13, the technical requirements leaflet of the Research Group for Roadways and Traffic ${ }^{[7]}$ was also used, because the leaflet includes requirements, which are sensible in regard to the assurance of the quality of the construction of stabilized layers. It deals especially with the requirements concerning the limits of the particle size distribution of the rounded gravel material,

which is to be used and the determination of the marginal value of the void content.

With selecting the proper mine material, the grain distribution, optimum water content, maximum dry density and type of bitumen emulsion were determined. As an example for the material from the excavation site at $\mathrm{km} 26.60$ are the results of grain size distribution as shown in Fig. 1. The consumed cement used in laboratory tests was type II Portland cement. Bitumen emulsion used was cationic slow setting (CSS) with $\mathrm{pH}$ of 2.5. The aggregates and consumed bitumen emulsion properties are shown in Table 1-3 respectively.

First Series Test Results Analysis: At first stage and to determine the optimum cement and bitumen emulsion, a total of 153 mixed designs, in four series of Marshal Tests were made and tested. The first three series included 27 samples with constant cement percentages of 1.5, 2 and $2.5 \%$ and variation of bitumen emulsion from $2.5,3$ and $3.5 \%$ respectively. The fourth series of tests were 72 samples with various cement percentage of $0.5,1,1.5,2,2.5,3,3.5$ and $4 \%$ with variation of bitumen emulsion from $2.5,3$ and $3.5 \%$.

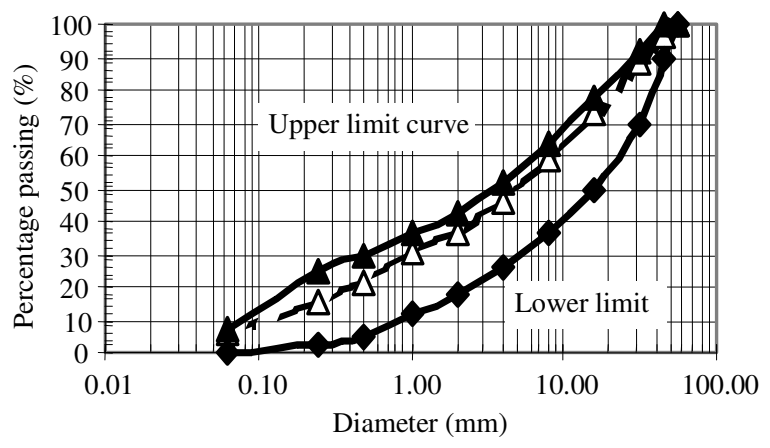

Fig. 1: Grain distribution of material

Table 1: Technical specification of the test materials

\begin{tabular}{lllllllll}
\hline $\begin{array}{l}\text { Unified } \\
\text { classification }\end{array}$ & Plasticity & $\begin{array}{l}\text { Sand } \\
\text { equivalent } \\
(\%)\end{array}$ & $\begin{array}{l}\text { D60 } \\
(\mathrm{mm})\end{array}$ & $\begin{array}{l}\mathrm{D} 30 \\
(\mathrm{~mm})\end{array}$ & $\begin{array}{l}\mathrm{D} 10 \\
(\mathrm{~mm})\end{array}$ & CC & CU \\
\hline SP & NP & 82 & 9 & 1 & 0.13 & 1.17 & 69 \\
\hline
\end{tabular}

Table 2: Bitumen specification for producing bitumen emulsion

\begin{tabular}{lllll}
\hline $\begin{array}{l}\text { Penetration index } \\
\text { at } 25^{\circ} \mathrm{C} \text { and } \\
\text { softening point }\end{array}$ & $\begin{array}{l}\text { Flash } \\
\text { point } \\
\left({ }^{\circ} \mathrm{C}\right)\end{array}$ & $\begin{array}{l}\text { Softening } \\
\text { point } \\
\left({ }^{\circ} \mathrm{C}\right)\end{array}$ & $\begin{array}{l}\text { Penetration } \\
\text { at } 25^{\circ} \mathrm{C}\end{array}$ & $\begin{array}{l}\text { Unit } \\
\text { weight } \\
\text { at } 25^{\circ} \mathrm{C}\end{array}$ \\
\hline-0.27 & 320 & 52 & 60 & 1.012
\end{tabular}

Table 3: Bitumen emulsion specification

\begin{tabular}{lllll}
\hline Specification & Bitumen $60-70$ & Water & Emulsifier & Solvent \\
\hline Producing temperature $\left({ }^{\circ} \mathrm{C}\right)$ & 140 & 30 & $30-40$ & Oct-40 \\
Unit weight during production $\left(\mathrm{g} \mathrm{cm}^{-3}\right)$ & 0.95 & 1 & 1.07 & 0.8 \\
Percentage by weight $(\%)$ & 58 & 39.75 & 1 & 1.15 \\
\hline
\end{tabular}




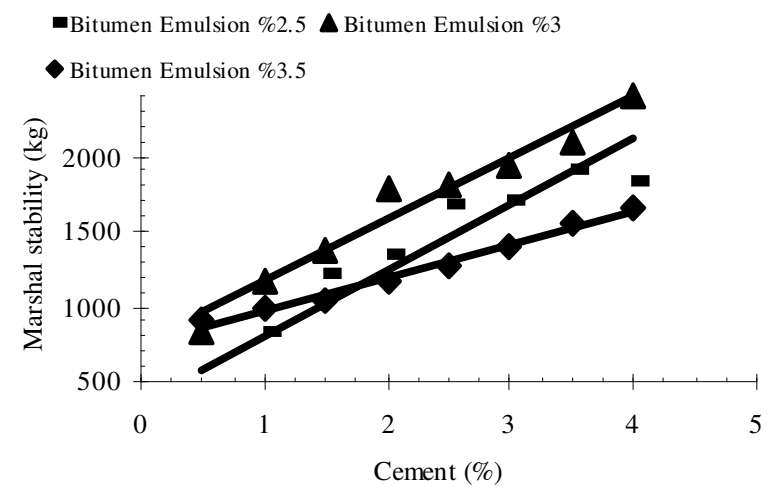

Fig. 2: Marshal stability versus Cement (7 days)

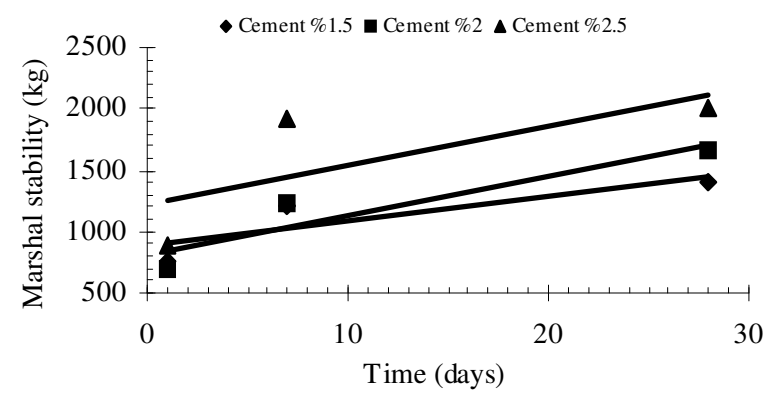

Fig. 3: Marshal stability versus time for $3 \%$ bitumen emulsion

The average test results for optimizing cement and bitumen emulsion are shown in Fig. 2 and 3.

Figure 2 shows the variation of Marshal Stability versus cement for $2.5,3$ and $3.5 \%$ of bitumen emulsion after seven days curing. The results indicate that, with increase in cement percentage the stability for all three series of tests increases; however, the samples with 3\% of bitumen emulsion shows the average difference of $30 \%$ more increase in stability in compare with 2.5 and $3.5 \%$ bitumen emulsions samples, thus, it seems choosing 3\% for bitumen emulsion may contribute the predicted strength results in stabilizing the base course. Thus, it was decided to choose this value as an optimum bitumen emulsion for our mixture.

For optimizing the amount of cement, the variation of Marshal Stability versus cement was plotted for constant 3\% of bitumen emulsion in Fig. 3. The results show that, the stability increase with increase in cement, but it is not possible to find optimum cement needed properly. Since using too much cement in the mixture, causes shrinkage cracks which, is a big problem for pavement structure and layers from water penetration viewpoint and also increase the unit cost, a new series of ITS and UCS tests carried out to optimize the percentage of cement and minimize the costs.

In second series of experimental tests, stabilization mix design method used. In recent years, the mechanical tests such as ITS, is standard criterion for determination of mix strength against fatigue cracks in all mix designs and usually UCS tests are performed along $\operatorname{ITS}^{[8-11]}$.

Unconfined compression strength test is an indirect method for determination of shear strength and specifically the cohesion of the material. The details and test specification are given in laboratory standards such as ASTM D1074-02, Australian AS 1141.51 and South African TMH1 A14. For this aim, the cylindrical sample is tested under axial stress and at breaking point; the strength is recorded as UCS value. The capacity of compression test machine used in this research was $200 \mathrm{kPa}$ with resolution of $0.1 \mathrm{kN}$. The application force velocity was $140 \mathrm{kPa}$ per second. The UCS values were calculated from the following equation:

$$
\mathrm{UCS}=\frac{4 \mathrm{P}}{\pi \mathrm{D}^{2}}
$$

where, UCS $=$ unconfined compression strength $(\mathrm{kPa})$, $\mathrm{P}=$ ultimate load $(\mathrm{kN})$ and $\mathrm{D}=$ sample diameter $(\mathrm{m})$.

Using cylindrical sample or extruded cores from stabilized layer, the indirect tensile strength of the samples are determined by applying load on lateral surface of the sample as follows:

The samples are made by segregation of materials greater than $19 \mathrm{~mm}$ and then, are compacted to $100 \%$ according to modified AASHTO specification. The height of samples are made $150 \pm 30 \mathrm{~mm}$. The sample curing method is similar to the specification explained earlier for unconfined compression strength test. The samples are sited between jaw shape accessory of the equipment rig and a force equal to $0.1 \mathrm{kN}$ is applied to settle the sample between the jaw holders and then, the sample is loaded with the rate of $40 \mathrm{kN}$ per minute up to breaking point. The ultimate breaking load is measured with a resolution of $0.1 \mathrm{kN}$.

The details and test method is given in laboratory Standards such as AASHTO T283, ASTM D4123, Australia AS 2891.13.1, South African TMH1 A16T and Austrian RVS 8S.05.13. The indirect tensile strength of samples was calculated as follows:

$$
\mathrm{ITS}=\frac{2 \mathrm{P}}{\pi \times 1 \times \mathrm{d}}
$$


where, ITS is indirect tensile strength $(\mathrm{kPa}), \mathrm{P}$ is the maximum load $(\mathrm{kN}), 1$ is the length of sample $(\mathrm{m})$ and, $\mathrm{d}$ is the diameter of the sample $(\mathrm{m})$.

The ITS was calculated for each percentage of bitumen emulsion with resolution of $1 \mathrm{kPa}$ along with information given for maximum density, percentage of bitumen, optimum water content, average density and relative density. To carry out this method, a series of tests performed. The test program is shown in Table 4-6.

For determination of ITS and UCS for each mix design, nine samples were made, three of them were tested after 7 days and six samples were kept for the same goal after 28 days.

Each sample was made in the mould with diameter and height of $15 \mathrm{~cm}$ respectively. It was cured based on Austrian specification. For each mould, the soil grains were soaked in optimum water content and cement for one minute, mixed with emulsion in mixer for two minutes then; it was compacted with special related jack until the equivalent pressure was reached to 200 $\mathrm{kN}$.

To determine the optimum water content, the proctor test was applied and the results showed that, $\omega_{\text {opt }}=6.3 \%$ and $\gamma_{\mathrm{d}(\max )}=2.24 \mathrm{~g} \mathrm{~cm}^{-3}$. The liquefiers (bitumen emulsion and water) chose based on optimum water content. For curing the samples, the following actions performed:

- The compacted samples in moulds were kept in ambient temperature for $24 \mathrm{~h}$

- The samples were extruded from the moulds, weighed with accuracy of $1 \mathrm{~g}$ and the sample heights were measured with accuracy of $1 \mathrm{~mm}$

- The first series of samples were covered with plastic bags at temperature of $20 \pm 2$ Celsius for

Table 4: Test program with variation of bitumen emulsion and cement

\begin{tabular}{lllll}
\hline $\begin{array}{l}\text { Bitumen } \\
\text { emulsion }\end{array}$ & \multicolumn{2}{l}{ Cement (\%) } & & \\
$(\%)$ & 2 & 3 & 4 & 5 \\
\hline 2 & N1 & N5 & N9 & N13 \\
3 & N2 & N6 & N10 & N14 \\
4 & N3 & N7 & N11 & N15 \\
5 & N4 & N8 & N12 & N16 \\
\hline
\end{tabular}

Table 5: Test program with constant bitumen emulsion and variation of cement

\begin{tabular}{lllll}
\hline Cement $(\%)$ & 2 & 3 & 4 & 5 \\
\hline Test No. & N17 & N18 & N19 & N20 \\
\hline
\end{tabular}

Table 6: Test program with constant cement and variation of bitumen emulsion

\begin{tabular}{lllll}
\hline Bitumen emulsion (\%) & 2 & 3 & 4 & 5 \\
\hline Test No. & N21 & N22 & N23 & N24 \\
\hline
\end{tabular}

5 days with relative humidity of $95 \%$ and similar way for second series for 26 days

- The samples for both series were kept in refrigerator for $24 \mathrm{~h}$ with temperature of 5 Celsius before testing.

After curing the samples, they were tested and the indirect tensile strength; unconfined compression strength and modulus of elasticity of each sample were determined.

Flexibility and strength against continuous deformation are important parameters for stabilizing soils with additives. Increasing one additive parameter will decrease the other one. Thus, it is important to measure the tensile and shear strength against continuous deformation for each mix design.

Second series test results analysis: Figure 4 shows ITS values versus bitumen emulsion for various percentage of cement. The results for 7 days curing indicate that, with increasing bitumen emulsion to almost 3\%, the ITS values increase and then, decrease considerably for $5 \%$ cement curve but, for the other cement percentages, the variation of ITS is insignificant. This finding confirms the result obtained by Marshal Method. The plotted curves also show that, with a certain value of bitumen emulsion, with increase in cement, the ITS increase respectively.

Figure 5 shows similar plot curves to Fig. 4 but for 28 days curing. Results in both figures indicate that, cement has effectively influenced in ITS value. However, based on Austrian specification, the minimum acceptable ITS and UCS for mix design are 0.2 and $2.5 \mathrm{~N} \mathrm{~mm}^{-2}$ respectively for 7 days curing. Figure 5 shows, if we use $2 \%$ cement the ITS value is on border line and almost close to $0.2 \mathrm{~N} \mathrm{~mm}^{-2}$ for $3 \%$ of bitumen emulsion. Furthermore, due to heavy traffic load and the fact that, in construction site, the unit cost of bitumen is slightly more than cement, it seems using $3 \%$ of cement is more reliable.

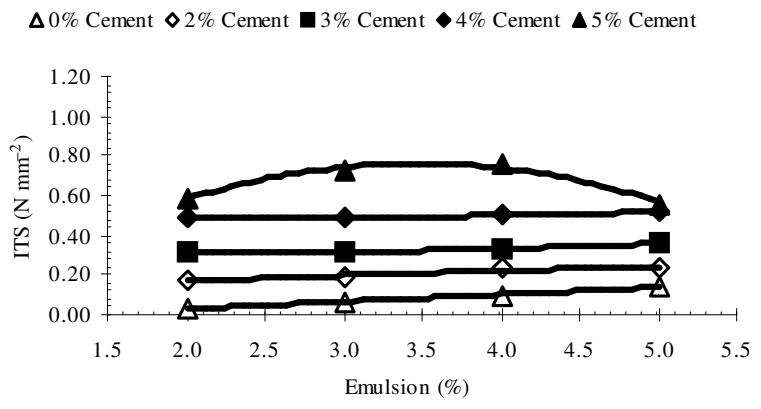

Fig. 4: ITS versus bitumen emulsion (7 days) 


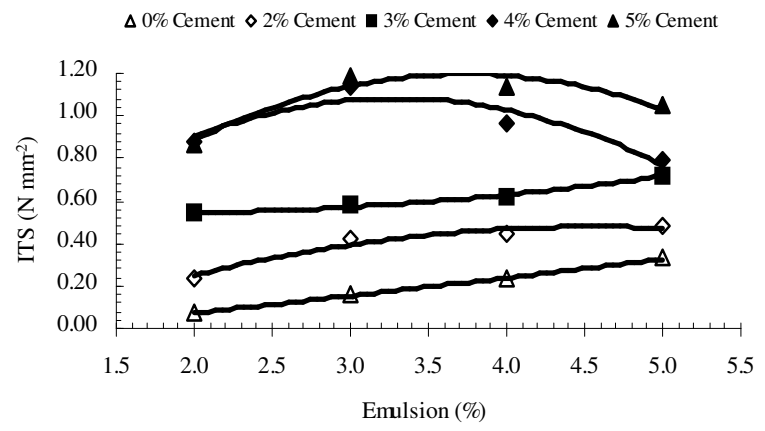

Fig. 5: ITS versus bitumen emulsion (28 days)

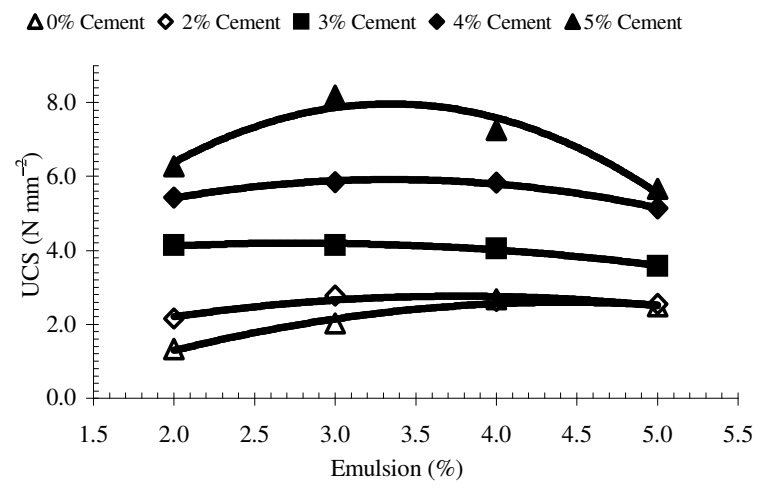

Fig. 6: UCS versus bitumen emulsion (28 days)

Figure 6 shows the UCS versus bitumen emulsion for various cement percentages. The results indicate that, in all plot curves, the UCS increase with increase in cement value. The plot curves also show that, the UCS reaches to its maximum value when bitumen emulsion is 3\%. Again this finding confirms the value of $3 \%$ for bitumen emulsion optimum from Marshal Series of tests.

Modulus of elasticity versus bitumen emulsion is plotted in Fig. 7. Figure 7 shows that, for a certain bitumen emulsion, with increase in cement, E-Module increase up to $4 \%$ and decreases afterward, while, when cement increase to $\% 5$, the modulus of elasticity decreases considerably. This might be due to the chemical reaction of cement-bitumen emulsion in the mixture.

According to traffic statistics obtained from construction site in Afghanistan and E-Module of 1500 MPa used for design, Fig. 7 shows that, the minimum cement which, can be used to get E-Module of 1500 MPa is 3\%. Thus, it seems the optimum value for both bitumen emulsion and cement for our design criteria is $3 \%$ respectively.

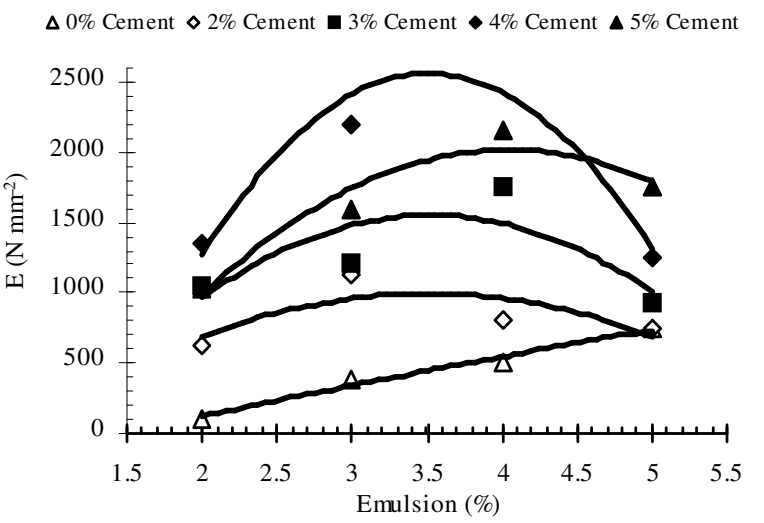

Fig. 7: Modulus of elasticity versus bitumen emulsion (28 days)

The results of this series of the tests indicate that, the roles of the cement and bitumen emulsion in mixtures are increasing the stiffness and elasticity of the stabilized layer respectively. Increase in cement percentage will decrease the elasticity and consequently causes shrinkage cracks in the layer, thus, it seems using 3\% for both optimized cement and bitumen emulsion contribute the best results in stiffness and elasticity, this was observed visually and by measurements, one year after the construction was finished.

\section{DESIGN METHODS}

The main road was designed with two methods, conventional variant and stabilizing with cement and bitumen emulsion variant. The PADS Software ${ }^{[12,14]}$ used for determination of layer thickness. In this way, the fatigue functions for pavement layers are extracted from Shell Pavement Design Method ${ }^{[13]}$. The new fatigue functions are based on fatigue specifications for stabilized layers with cement. It also presents a new method for calculation of combined bitumen emulsion and cement. The design parameters and traffic load are extracted as follows:

For asphalt layers, the stiffness coefficient is extracted from $\operatorname{SPDM}^{[13]}$ and functions used for calculation were (Table 7):

- Function S1-50 for surface course

- Function S2-50 for binder course and black-base

- The mean yearly ambient temperature for the layers, $25^{\circ} \mathrm{C}$ 
Am. J. Applied Sci., 6 (1): 30-42, 2009

Table 7: Input data-layer specification

\begin{tabular}{lll}
\hline Pavement layers & $\begin{array}{l}\text { Module of } \\
\text { elasticity }(\mathrm{MPa})\end{array}$ & $\begin{array}{l}\text { Poisson } \\
\text { ratio }\end{array}$ \\
\hline Surface course S1-50 & 3000 & 0.35 \\
Binder course S2-50 & 1500 & 0.35 \\
Black-base S2-50 & 1500 & 0.35 \\
$\begin{array}{l}\text { Binder course with high performance } \\
\text { Black-base with high performance }\end{array}$ & 2500 & 0.35 \\
$\begin{array}{l}\text { Stabilized layer with cement and } \\
\text { bitumen emulsion }\end{array}$ & 2500 & 0.35 \\
Sub-base & 1500 & 0.35 \\
Sub-grade & $300(\mathrm{CBR} \geq 60)$ & 0.35 \\
Underneath soil & $240(\mathrm{CBR} \geq 25)$ & 0.35 \\
\hline
\end{tabular}

Table 8: Input data-loads and axles

\begin{tabular}{lll}
\hline Axle type & Wheel load $(\mathrm{kN})$ & Tire pressure $(\mathrm{kPa})$ \\
\hline $80 \mathrm{kN}$ tandem axles & 20 & 577 \\
$100 \mathrm{kN}$ single axle & 50 & 700 \\
$115 \mathrm{kN}$ single axle & 57.5 & 800 \\
\hline
\end{tabular}

Table 9: Design calculation-stabilized layer with cement and bitumen emulsion

\begin{tabular}{lll}
\hline Pavement layers & $\begin{array}{l}\text { Module of } \\
\text { elasticity }(\mathrm{MPa})\end{array}$ & $\begin{array}{l}\text { Thickness } \\
(\mathrm{mm})\end{array}$ \\
\hline $\begin{array}{l}\text { Asphalt layer } \\
\text { Stabilized layer with cement } \\
\text { and bitumen emulsion }\end{array}$ & 3000 & 50 \\
$\begin{array}{l}\text { Sub-grade } \\
\text { Sub-soil }\end{array}$ & 1500 & 250 \\
$\begin{array}{l}\text { Standard allowed axle repitition } \\
80 \mathrm{kN} \text { tandem axle }=7.33 \times 10^{6}\end{array}$ & $240(\mathrm{CBR} \geq 25)$ & 600 \\
$100 \mathrm{kN}$ single axle $=1.61 \times 10^{6}$ & & $\geq 1000$ \\
$115 \mathrm{kN}$ single axle $=1.13 \times 10^{6}$ & & \\
\hline
\end{tabular}

In second variant, in spite of above items and assuming asphalt layers with higher module of elasticity, excess calculations were carried out. For stabilized layer, the selected design E-Module was less than the value obtained from the fatigue tests.

According to traffic statistics obtained from construction site area in Afghanistan, three types of loading were considered in calculations: 80 and $100 \mathrm{kN}$ for tandem axles and $115 \mathrm{kN}$ for single axle. Details of input data are shown in Table 8 and 9.

Design was made with different E-Module for asphalt layers. The results indicate that, the asphalt layer with normal stiffness module is not proper for high loading traffic condition such in Afghanistan. Thus, calculations repeated with higher E-Module to find out the effect of stiffness on ultimate structure bearing capacity. Design results are presented in Table 10-12. The results of the design methods revealed the following features:

The calculated figures shown in Table 10 and 11 indicate that, using $80 \mathrm{kN}$ tandem axle with $20 \mathrm{kN}$ wheel load as a designed axle load, show higher bearing capacity for the first variant i.e., conventional method in compare with stabilized layer (second variant).
Table 10: Design calculation-asphalt layer (conventional method)

\begin{tabular}{lll}
\hline Pavement layers & $\begin{array}{l}\text { Module of } \\
\text { elasticity }(\mathrm{MPa})\end{array}$ & $\begin{array}{l}\text { Thickness } \\
(\mathrm{mm})\end{array}$ \\
\hline Surface course & 3000 & 40 \\
Binder course & 1500 & 60 \\
Black-base & 1500 & 60 \\
Sub-base & $300(\mathrm{CBR} \geq 60)$ & 150 \\
Sub-grade & $240(\mathrm{CBR} \geq 25)$ & 600 \\
Sub-soil & $100(\mathrm{CBR} \geq 10)$ & $\geq 1000$ \\
Standard allowed axle repitition & & \\
$80 \mathrm{kN}$ tandem axle $=0.66 \times 10^{9}$ & & \\
$100 \mathrm{kN}$ single axle $=0.26 \times 10^{6}$ & & \\
$15 \mathrm{kN}$ single axle $=0.13 \times 10^{6}$ & & \\
\hline
\end{tabular}

Table 11: Design calculation-asphalt layer with high performance (conventional method)

\begin{tabular}{lll}
\hline Pavement layers & $\begin{array}{l}\text { Module of } \\
\text { elasticity }(\mathrm{MPa})\end{array}$ & $\begin{array}{l}\text { Thickness } \\
(\mathrm{mm})\end{array}$ \\
\hline Surface course & 3000 & 40 \\
Binder course & 2500 & 60 \\
Black-base & 2500 & 60 \\
Sub-base & $300(\mathrm{CBR} \geq 60)$ & 150 \\
Sub-grade & $240(\mathrm{CBR} \geq 25)$ & 600 \\
Sub-soil & $100(\mathrm{CBR} \geq 10)$ & $\geq 1000$ \\
Standard allowed axle repitition & & \\
$80 \mathrm{kN}$ tandem axle $=2.81 \times 10^{9}$ & & \\
$100 \mathrm{kN}$ single axle $=0.44 \times 10^{6}$ & & \\
$115 \mathrm{kN}$ single axle $=0.23 \times 10^{6}$ & & \\
\hline
\end{tabular}

Table 12: Temperature of construction

\begin{tabular}{lll}
\hline Temperature ${ }^{\circ} \mathrm{C}$ & From km & Section $(\mathrm{km})$ \\
\hline 10,0 & 0,000 & $0,000-23,000$ \\
12,0 & 7,600 & \\
15,0 & 14,500 & \\
15,0 & 0,000 & $0,000-23,000$ \\
12,0 & 9,100 & \\
10,0 & 18,600 & $23,000-32,300$ \\
16,0 & 23,000 & \\
10,0 & 24,900 & $23,000-32,300$ \\
12,0 & 23,000 & \\
10,0 & 27,200 & \\
\hline
\end{tabular}

However, assuming low axle load for the main road in Herat-Dogharoun with very high traffic loads is strictly improper and this variant may not be advised.

Since the heavy trucks in Afghanistan loading with more than $600 \mathrm{kN}$, the design results show that, only using 100 or $115 \mathrm{kN}$ may satisfy the design concept for the real traffic road.

\section{QUALITY CONTROL}

To ensure the quality of stabilized layer with cement and bitumen emulsion, tests on material used performed on daily bases. The tests were: soil gradation, water content, compacted densities in laboratory and in-situ, compaction rate, ITS and UCS tests. 
Am. J. Applied Sci., 6 (1): 30-42, 2009

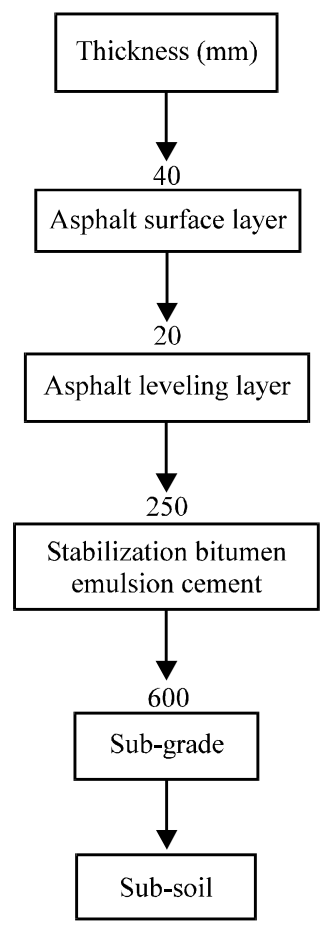

Fig. 8: Section No.1 km 0,000 -km 23,000

FWD measurements in three constructed sections: The FWD measurements were carried out in the sections $\mathrm{km} \mathrm{0,000} \mathrm{-} \mathrm{km} \mathrm{23,000,} \mathrm{km} \mathrm{23,000} \mathrm{-} \mathrm{km} \mathrm{32,300}$

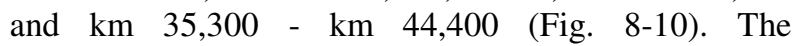
measurements net were determined in correspondence to the roadway with an interval of 50 meters. Through this measurement disposition an exact analysis of the actual bearing capacity of the roadway construction becomes possible.

The bearing capacity evaluation using FWD results: Through the data from the measured deflection moulds, the recalculation of the layer specific E-Module values was carried out for the following layers of the construction:

Layer No. 1: asphalt construction, reference temperature $25^{\circ} \mathrm{C}$, layer No. 2: stabilization with bitumen emulsion and cement, layer No. 3: sub-grade and Layer No. 4: soil

The recalculation of the layer specific E-Module values was carried out according to the following method.

Implementing a suitable model and the appropriate material constants, a theoretical deformation curve can be calculated and compared with the actual measured

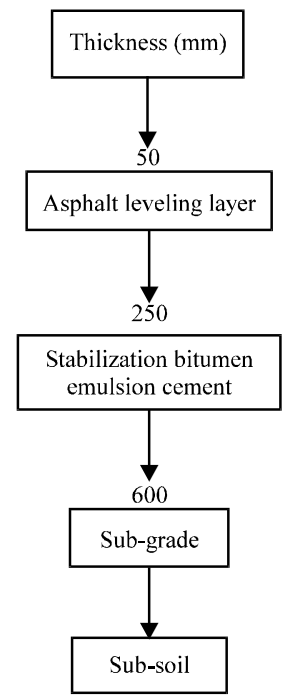

Fig. 9: Section No.2 km 23,000 -km 32,300

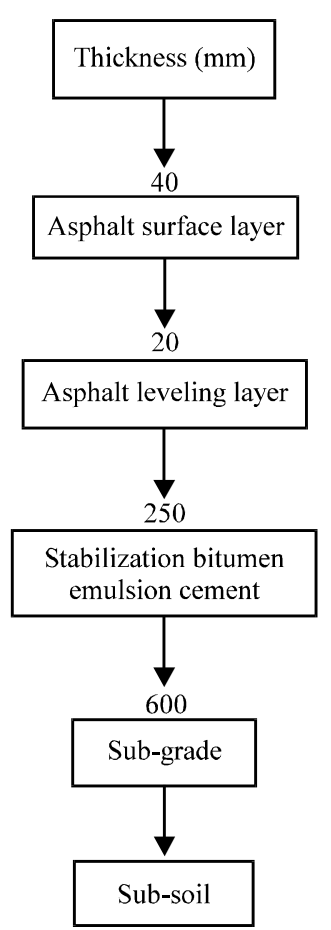

Fig. 10: Section No.3 km 35,300 -km 44,400

one. If the two curves do not match with each other, the input values must be varied so long until the best possible match is achieved. For flexible pavement structures a multi-layer system is used for a model. Whereby the single layers are assumed idealized (i.e., homogeneous, linear elastic and isotropic) and described by the dynamic E-Module, the Poisson ratio 
Am. J. Applied Sci., 6 (1): 30-42, 2009

(connection between longitudinal and lateral elongation) and the thickness of layer.

For these recalculations, the dynamic E-Module values are the only degree of freedom for the individual layers, because the Poisson ratio can sufficiently accurately be selected.

The dynamic E-Module values of the layers allow interference for the load bearing capacity and the condition of the single layers and can be compared with reference values. Furthermore, the stresses and strains (elongations) in the structure under a given load can be defined.

Before starting the back-calculation of the EModule values, the deflection moulds must be analyzed precisely and following evaluation steps taken:

- First of all, the deflections recorded on each geophone are converted linear to standard force of $100 \mathrm{kN}$. Thereafter, these converted data are divided into homogeneous sections. This step is required because a great number of measurements taken by falling weight equipment usually have an uneven distribution of the deflection values. It is expedient to summaries the measured values into larger sections with approx. homogeneous relation and to evaluate them together. To find these sections the method of cumulative sums is used. Simplified, the single values are statistically registered and divided into height of deflection. The homogeneous section results itself as turning point of the curve where, the deflections of the measuring points are plotted

- The significance of the compiled sections is determined. In the statistical analysis of the falling weight measurements of the single runway sections and for each homogeneous section and direction lane, an analysis of the mean, standard deviation and variation has been done. For each section and $85 \%$ deflection mould has been determined. As last step, a characteristic E-Module value for the statistical determined $85 \%$ deflection mould representing the complete homogeneous section has been calculated

- All material constants are subjected to specific variations, therefore, it is reasonable to calculate for the various measuring lines the statistical 50, 60, 70, 85, 90 and 95\% deflection moulds. The results of these recalculations show very well the actual variations found in practice for the EModules of the single layers. Depending on the defaulted safety level, one of the given profiles can be selected
- The pavement structure is described as a linear, elastic multi-layered system. The determination of the E-Modules is done by iteration. The surface module according to Boussinesq is used to derive the bearing capacity of the Sub-grade directly from the measured results. It is also used to recognize stiff or lesser stiff layers in the sub-grade. By means of one first estimate of the E-Modules of the remaining two layers, a deflection profile is computed and compared with the characteristic (measured) bending profile. If the difference between the calculated and the measured bending profile is big, the assumption of the E-Module is changed so long until the computed profile matches the measured bending profile. The so determined Elasticity Modules are representative for the whole section

The temperature of the roadway construction was digitally registered during the measurements. Decisive for the determination of the dynamic E-Module values of the layer bound with bitumen is the temperature of the construction during the moment of measurement. The temperature of the construction bound with bitumen was measured on the surface and on the under edge of the stabilized layer. Table 12 shows the results of the continual temperature measurements.

The evaluated results of the measurements with FWD split up into three sections and for each direction lane. Based on the measured deflection moulds for each section and each direction lane, the E-Module values for each homogeneous section are recalculated and a sample FWD test results for $\mathrm{km} \mathrm{0,000-23,000}$ directions to Heart is presented in Table 13.

Result analysis and discussion of the design calculations according to the actual bearing capacity of the construction: The reference values for the calculations were the weighted mean E-Module values calculated for each of the three sections of the roadway. The design calculations were carried out with the Software-PADS ${ }^{[12]}$. The following reference values were also included: Load: single axle $115 \mathrm{kN}$, tire load $57.5 \mathrm{kN}$, tire pressure 8 bar $(800 \mathrm{kPa})$. Poisson ratio: 0.35 used for asphalt, stabilization, sub-grade and the soil.

The result of the design calculation according to the actual bearing capacity of the roadway construction in the three evaluated sections of the roadway HeartDogharoun is presented in Table 14. The results show that, the bearing capacity of the pavement measured in the three sections of the roadway is very favorable and are more than assumed ones in design procedure. The 
Am. J. Applied Sci., 6 (1): 30-42, 2009

Table 13: FWD test results for $\mathrm{km} 0,000$ to $\mathrm{km} 23,000$ directions to herat

\begin{tabular}{|c|c|c|c|c|c|c|c|c|}
\hline & \multicolumn{4}{|c|}{ E-module } & \multicolumn{4}{|c|}{ Layer thickness } \\
\hline & $\begin{array}{l}\text { Layer } 1 \\
(\mathrm{Mpa})\end{array}$ & $\begin{array}{l}\text { Layer } 2 \\
\text { (Mpa) }\end{array}$ & $\begin{array}{l}\text { Layer } 3 \\
(\mathrm{Mpa})\end{array}$ & $\begin{array}{l}\text { Layer } 4 \\
(\mathrm{Mpa})\end{array}$ & $\begin{array}{l}\mathrm{t} 1 \\
(\mathrm{~mm})\end{array}$ & $\begin{array}{l}\mathrm{t} 2 \\
(\mathrm{~mm})\end{array}$ & $\begin{array}{l}\mathrm{t} 3 \\
(\mathrm{~mm})\end{array}$ & $\begin{array}{l}\text { Lack of } \\
\text { Fit }(\%)\end{array}$ \\
\hline \multicolumn{9}{|c|}{ Recalculation of E-module values for the statistic deflection profiles total measuring line } \\
\hline 50\%-Profile & 3271 & 7200 & 200 & 423 & 60 & 250 & 600 & 3.7 \\
\hline $60 \%$-Profile & 3146 & 7000 & 200 & 380 & 60 & 250 & 600 & 3 \\
\hline 70\%-Profile & 3062 & 6700 & 198 & 350 & 60 & 250 & 600 & 2.6 \\
\hline $85 \%$-Profile & 2852 & 6500 & 190 & 305 & 60 & 250 & 600 & 2.7 \\
\hline $90 \%$-Profile & 2726 & 6200 & 185 & 291 & 60 & 250 & 600 & 3.5 \\
\hline \multicolumn{9}{|c|}{ Recalculation of E-Module values for the statistic deflection profiles } \\
\hline $85 \%$ Profile & 4483 & 5500 & 108 & 267 & 60 & 250 & 600 & 3.3 \\
\hline $85 \%$ Profile & 3958 & 6000 & 150 & 316 & 60 & 250 & 600 & 2.1 \\
\hline $85 \%$ Profile & 3479 & 8250 & 280 & 216 & 60 & 250 & 600 & 2.2 \\
\hline $85 \%$ Profile & 4270 & 5500 & 195 & 284 & 60 & 250 & 600 & 3.1 \\
\hline $85 \%$ Profile & 3541 & 6500 & 200 & 420 & 60 & 250 & 600 & 3.8 \\
\hline $85 \%$ Profile & 3240 & 4850 & 324 & 576 & 60 & 250 & 600 & 1.7 \\
\hline $85 \%$ Profile & 3751 & 6500 & 224 & 420 & 60 & 250 & 600 & 2.5 \\
\hline $85 \%$ Profile & 3315 & 5600 & 245 & 560 & 60 & 250 & 600 & 4.6 \\
\hline $85 \%$ Profile & 3581 & 3600 & 150 & 550 & 60 & 250 & 600 & 5.4 \\
\hline $85 \%$ Profile & 3342 & 5400 & 187 & 365 & 60 & 250 & 600 & 3.5 \\
\hline $85 \%$ Profile & 2451 & 4500 & 170 & 335 & 60 & 250 & 600 & 6 \\
\hline $85 \%$ Profile & 3605 & 4500 & 182 & 320 & 60 & 250 & 600 & 2.5 \\
\hline $85 \%$ Profile & 3028 & 8600 & 147 & 340 & 60 & 250 & 600 & 2.9 \\
\hline
\end{tabular}

Table 14: Average statistical calculation of e-modules of heart-dogharoun road

\begin{tabular}{|c|c|c|c|c|}
\hline \multirow[b]{2}{*}{ Section } & \multicolumn{4}{|c|}{ Modulus of elasticity $\left(\mathrm{N} \mathrm{mm}^{-2}\right)$} \\
\hline & 1st Layer At $25^{\circ} \mathrm{C}$ & 2nd Layer & 3rd Layer & 4th Layer \\
\hline $00.00-23.00 \mathrm{~km}$ & 3605 & 5735 & 203 & 376 \\
\hline $23.00-32.30 \mathrm{~km}$ & 3128 & 5234 & 148 & 399 \\
\hline $35.30-44.40 \mathrm{~km}$ & 3493 & 5432 & 223 & 294 \\
\hline Layer No. & \multicolumn{2}{|l|}{ Type of layer } & \multicolumn{2}{|c|}{ Layer thickness (mm) } \\
\hline 1 & \multicolumn{2}{|l|}{ Asphalt } & \multicolumn{2}{|c|}{50 or 60} \\
\hline 2 & \multicolumn{2}{|c|}{ Stabilization with cement and bitumen } & \multicolumn{2}{|l|}{250} \\
\hline 3 & \multicolumn{2}{|c|}{ Sub-grade } & \multicolumn{2}{|l|}{600} \\
\hline 4 & \multicolumn{2}{|l|}{ Soil } & \multicolumn{2}{|l|}{$\infty$} \\
\hline
\end{tabular}

Table 15: The allowed standard axles for three evaluated sections

\begin{tabular}{ll}
\hline Section & Allowed Standard Axle of $115 \mathrm{kN}$ \\
\hline $\mathrm{Km} 0,00-\mathrm{Km} \mathrm{23,00}$ & $6.52 \times 10^{6}$ \\
$\mathrm{Km} 23,00-\mathrm{Km} \mathrm{32,30}$ & $6.14 \times 10^{6}$ \\
$\mathrm{Km} 35,30-\mathrm{Km} \mathrm{44,40}$ & $6.80 \times 10^{6}$ \\
\hline
\end{tabular}

permissible standard axle load repetitions, corresponding with the standard axle load of $115 \mathrm{kN}$ is more than $6 \times 10^{6}$ for three evaluated sections (Table 15). This means that the construction has a very high bearing capacity in comparison to the assumptions.

Construction cost analysis: Cost analysis of onekilometer roadway constructed in Heart Dogharoun which, is based on Iranian Management and Programming Organization (MPO) and is presented in Table 16. Cost analysis made only using base unit costs and none of the coefficients such as: hardness, traffic, regional and etc. are not included.

It is important to note that; there are many items involved in construction costs such as bridges, excavations, filings, embankments and etc. that are similar for both methods of base stabilized and conventional and are not included here. The analysis is made only to show the cost difference between the two alternatives.

The results shown in Table 16 indicate that, in spite of some difference in total costs between two alternatives (about 7\%), an important item, which is not included in these results, is the time factor. To carry out the conventional method, it was necessary to haul the sub-base material from almost 69 kilometers from the construction site, which, costs about 14,231 USD and more important was the execution period which, must be increased to almost twofold in compare with the second alternative. It means, four years needed to finish the project if the conventional method was used while; the total 122 kilometers job was finished less than two years.

Another important aspect was the economic situation in the region and, because of civil war, in 
Am. J. Applied Sci., 6 (1): 30-42, 2009

Table 16: Comparison cost analysis of $1 \mathrm{~km}$ base stabilized roadway with conventional pavement

\begin{tabular}{|c|c|c|c|c|c|c|c|}
\hline & Surface course & Tack-coat & Binder course & Prime-coat & Stabilized-base & \multicolumn{2}{|l|}{-} \\
\hline \multicolumn{8}{|c|}{ Base-stabilized using cement and bitumen emulsion method } \\
\hline \multicolumn{8}{|l|}{ Unit } \\
\hline$\left(\mathrm{m}^{2}-\mathrm{cm}\right)$ & 30,000 & - & 22,000 & - & 275,000 & \multicolumn{2}{|l|}{-} \\
\hline$(\mathrm{kg})$ & - & 1,500 & - & 5,500 & - & \multicolumn{2}{|l|}{-} \\
\hline \multicolumn{8}{|l|}{ Unit cost } \\
\hline $\mathrm{USD} \mathrm{m}^{-2}-\mathrm{cm}$ & 0.67 & - & 0.61 & - & 0.32 & \multicolumn{2}{|l|}{-} \\
\hline $\mathrm{USD} \mathrm{kg}^{-1}$ & - & 0.31 & - & 0.30 & - & \multicolumn{2}{|l|}{-} \\
\hline Total unit cost (USD) & 20,100 & 465 & 13,420 & 1,650 & 88,000 & \multicolumn{2}{|l|}{-} \\
\hline Total cost per km (USD) & 123,635 & & & & & & \\
\hline \multicolumn{8}{|c|}{ Asphalt layer with high performance (conventional method) } \\
\hline & Surface course & Tack-coat & Binder course & Tack-coat & Black-base & Prime-coat & Sub-base \\
\hline \multicolumn{8}{|l|}{ Unit } \\
\hline$\left(\mathrm{m}^{2}-\mathrm{cm}\right)$ & 30,000 & - & 66,000 & - & 66,000 & - & - \\
\hline$(\mathrm{kg})$ & - & 1,500 & - & 1,500 & - & 13,200 & - \\
\hline $\mathrm{m}^{3}$ & - & - & - & - & - & - & 1,650 \\
\hline \multicolumn{8}{|l|}{ Unit cost } \\
\hline $\mathrm{USD} \mathrm{m}^{-2}-\mathrm{cm}$ & 0.67 & & 0.61 & - & 0.57 & - & - \\
\hline $\mathrm{USD} \mathrm{kg}^{-1}$ & - & 0.31 & - & 0.31 & - & 0.30 & - \\
\hline USD m ${ }^{-3}$ & - & - & - & - & - & - & 6.70 \\
\hline \multicolumn{8}{|c|}{ Sub-base extra unit hauling cost } \\
\hline USD $\mathrm{km}^{-1}$-ton $>30 \mathrm{~km}<70 \mathrm{~km}$ & - & - & - & - & - & - & 0.05 \\
\hline Total unit cost (USD) & 20,100 & 465 & 33,550 & 465 & 37,620 & 3,960 & 19,099 \\
\hline Total cost $\mathrm{km}^{-1}$ (USD) & 115,259 & & & & & & \\
\hline
\end{tabular}

Afghanistan; the inflation rate was two high, which could increase the costs effectively if the project could not be finished as early as possible. However, in spite of high chemical binding costs, not only in developed countries but also, in undeveloped countries such as Afghanistan, using stabilization variant may effect the construction time period and consequently decrease the construction costs effectively.

\section{RESULTS}

The overall results of this research revealed that:

- Based stabilized using combined cement and bitumen emulsion increases the bearing capacity of the pavement effectively. This causes considerable increase in number of allowable equivalent standard axle load (ESAL) and consequently, the lifetime of the road will increase respectively

- The total roadway layers in second variant decreased in compare to conventional variant, which, influence the construction time period effectively.

- Base stabilization is capable for high limit of loading in the regions with lack of proper material

- In spite of high chemical binding costs, not only in developed countries but also, in undeveloped countries such as Afghanistan, using stabilization variant may affect the construction costs effectively

\section{ACKNOWLEDGMENT}

We would like to express our sincere appreciation to Nievelt Labor Company for providing FWD and GPR equipments for carrying out our measurements.

\section{REFERENCES}

1. Hicks, Gary, R., 2002. Soil stabilization design guide. State of Alaska Department of Transportation and Public Facilities. Research and Technology Transfer, Fairbanks.

2. Michell, J.K., 1981. Soil improvement-state of the art report. Proc., 10th ICSMFE., 4: 509-565.

3. Fatani, M.N., G.E. Bauer and N.A. Aljoulani, 1991. Reinforcing soil with aligned and randomly oriented metallic fibers. J. Geotech. Test., 14 (1): 78-87.

4. Baghdadi, Z.A., M.N. Fatani and N.A. Sabban, 1995. Soil modification by cement kiln dust. J. Mater. Civil Eng., 7 (4): 218-222.

5. Army, T.M. 5-822-14, 1994. Soil stabilization for pavements. Department of the Army, the Navy and the Air Force.

6. COST 336, 2000. Falling weight deflectometer. European Commission, Final Report of the Action. Transport Research, Directorate General Transport.

7. Austrian ZTVT-STB 95, 2002. Additional Technical Requirements and Guidelines for Base Courses in Roadway Construction. 
8. ASTM D 4123-82, 1987. Standard Method for Indirect Tension Test for Resilient Modulus of Bituminous Mixtures. American Society for Testing and Materials. West Conshohocken, Pennsylvania.

9. ASTM, 1994. Standard Guide for Evaluating Effectiveness of Chemicals for Soil Stabilization. D 4609-94 Annual Book of Standards. Vol. 04 (08) PA, USA.

10. Kennedy, T., 1977. Characterization of asphalt pavement materials using the indirect tensile test. Proceedings, the Association of Asphalt Paving Technologist, pp: 150-321.

11. Josteine, M., 2000. The Use of Cold Bitumen Stabilized Base Course in Norway. Norwegian Public Roads Administration, Akershus, Norway.
12. Theyse, H. and M. Muthen, 2000. Pavement Analysis and Design Software (PADS) based on the South African Mechanistic-Empirical Design Method. In: Transportation Infrastructure, South African Transport Conference. Pretoria, Paper $3 \mathrm{c} 75$.

13. SPDM, 1985. Shell International Petroleum Company Ltda. Addendum to the Shell Pavement Design Manual, London.

14. Theyse, H.L., 2000. Overview of the South African Mechanistic Pavement Design Method. South African Transport Conference. 